\title{
Mycobacterium tuberculosis and Phenotypic Drugs Susceptibility Tests
}

\section{Ahmet Yilmaz Coban*}

Department of Medical Microbiology, Ondokuz Mayis University, Samsun, Turkey

In this editorial, phenotypic drugs susceptibility test methods in Mycobacterium tuberculosis were discussed.

Determination of resistance patterns of Mycobacterium tuberculosis is an important step for management of tuberculosis patients [1]. Rapid automated systems (BACTEC MGIT 960 and BACTEC 460 TB) are available, too. Although they are rapid, their high cost and requiring radioactive substance are important disadvantages. Proportion method is the proposed reference method and it can be done on Middlebrook $7 \mathrm{H} 10$ and 11 agar and Lowenstein-Jensen medium. But the test applied on these media requires 4 weeks to obtain results [2]. Rapid and low cost methods that circumvent mentioned disadvantages have been defined recently. These methods include colorimetric redox indicator (CRI) methods (e.g. resazurin microplate and tube assay), nitrate reductase test (NRA), MTT, XTT, malachite green, microscopically observed drug susceptibiliy (MODS) and crystal violet decolorization tests (not published yet). CRI, NRA and MODS gained great concern and recommended by WHO. Susceptibility results obtained between 7 and 14 days by mentioned methods [3]. In conclusion, the first step is the determination of resistance pattern for effective treatment and controlling of tuberculosis.

\section{References}

1. Martin A, Portaels F, Palomino JC (2007) Colorimetric redox-indicator methods for the rapid detection of multidrug resistance in Mycobacterium tuberculosis: a systematic review and meta-analysis. J Antimicrob Chemother 59: 175-183.

2. Kent PT, Kubica GP (1985) Public health mycobacteriology. A guide 171 for the level III laboratory. U.S Department of Health and Human Services, Center for Disease Control and Prevention, Atlanta, GA, USA.

3. http://www.who.int/tb/laboratory/whopolicy_noncommercialculture_and dstmethods_july10_revnov10.pdf
*Corresponding author: Ahmet Yilmaz Coban, Medical School, Department of Medical Microbiology, Ondokuz Mayis University,55139, Samsun, Turkey, E-mail: yilmazden@hotmail.com

Received February 22, 2013; Accepted February 25, 2013; Published February 28,2013

Citation: Coban AY (2013) Mycobacterium tuberculosis and Phenotypic Drugs Susceptibility Tests. Clin Microbial 2: e109. doi:10.4172/2327-5073.1000e109

Copyright: (c) 2013 Coban AY. This is an open-access article distributed under the terms of the Creative Commons Attribution License, which permits unrestricted use, distribution, and reproduction in any medium, provided the original author and source are credited. 